\title{
PESQUISA DE SATISFAÇÃO DE CONSUMIDOR. UM LEVANTAMENTO (SURVEY) REALIZADO NA CONCESSIONÁRIA HONDA DE ITUVERAVA
}

\author{
LOPES, Ana Cláudia da Silveira ${ }^{1}$ \\ PIAZZA, Débora Cristina ${ }^{2}$ \\ BRANCO, Luiz Eduardo de ${ }^{3}$
}

Recebido em: 2009. 12. 08

Aprovado em: 2010.02 .14

ISSUE DOI: $10.3738 / 1982.2278-318$

RESUMO: A satisfação do cliente é essencial para o sucesso de toda empresa. As diversas pesquisas nesta área além de confirmarem isso, mostram que a satisfação é a grande responsável pelo retorno do cliente à empresa, assim como a insatisfação pode levar à perda de resultados. Este artigo teve como objetivo analisar os principais fatores de influência na satisfação (ou não) dos consumidores de uma concessionária de motos. Utilizou-se para tais finalidades, um levantamento (survey), que permitiu concluir entre outras coisas, que o atendimento e a marca Honda são os principais fatores de influência na satisfação dos consumidores da concessionária Moto Zema da cidade de Ituverava.

Palavras-chave: Pesquisa. Satisfação. Insatisfação. Concessionária. Moto Honda.

SUMMARY: The satisfaction of the customer is essential for the success of all company. The various research in this area beyond confirming this, shows that the satisfaction is great the responsible one for the return of the customer to the company, as well as the insatisfaction can lead to the loss of results. This article had as objective to analyze the factors main of influence in the satisfaction (or not) of the consumers of a motorcycle concessionaire. A survey was used for such purposes, that it allowed to conclude among others things, that the attendance and the Honda mark are the main factors of influence in the satisfaction of the consumers of the concessionaire Zema motorcycle of the Ituverava city.

Keywords: Survey. Satisfaction. Insatisfaction. Concessionaire. Motorcycle Honda.

\section{INTRODUÇÃO}

O mundo de hoje é altamente competitivo, onde todos buscam estar à frente de seus concorrentes. O grande desafio das empresas vai além da conquista do cliente, já que o conceito de cliente mudou. Cliente não é mais quem compra uma só vez, mas quem volta para comprar a segunda vez e daí por diante, outras vezes. Os empresários utilizam-se das mais variadas estratégias de marketing na tentativa de manter-se em um mercado cada vez mais competitivo, buscando continuamente satisfazer os consumidores, e quanto mais a

\footnotetext{
${ }^{1}$ Graduanda do Curso de Administração da Faculdade de Filosofia, Ciências e Letras de Ituverava/SP. Email:analopes_18@hotmail.com

${ }^{2}$ Graduanda do Curso de Administração da Faculdade de Filosofia, Ciências e Letras de Ituverava/SP. Email:débora.piazza@yahoo.com.br

${ }^{3}$ Administrador de empresas. Prof. Do Curso de Administração da Faculdade de Filosofia, Ciências e Letras de Ituverava/SP. E-mail: luizeduardo@stamaria.ind.br
} 
empresa volta-se para esse cliente, mais ela aproxima-se da tão almejada satisfação e do sucesso no ramo dos negócios.

Para Kotler e Armstrong (2003), marketing é um processo administrativo e social onde os indivíduos e grupos recebem o que necessitam e desejam, através da criação, oferta e troca de produtos. Segundo Kotler (2000), o profissional de marketing busca compreender as necessidades dos clientes, seus desejos e suas demandas. Essas necessidades transformam -se em desejos, quando são levadas à produtos específicos capazes de satisfazê-las. Demandas são desejos por certos produtos, onde existe a possibilidade de pagamento.

Conforme dito por Kotler e Armstrong (2003), a satisfação do cliente depende do que ele percebe do produto em relação às suas expectativas. Se as expectativas o corresponderem, ele ficará satisfeito, do contrário, ficará insatisfeito e se exceder às expectativas ele ficará maravilhado.

É desejo de toda empresa, ter seu cliente satisfeito e, por conseqüência, ter a fidelidade e, com ela, o lucro. Os teóricos, de modo geral, dizem que o lucro aumenta com o tempo, à medida que os clientes se tornam mais fiéis. Os consumidores deparam-se com um número cada vez maior de produtos, qualidade, estratégias de preços, promoções, marcas, serviços pós venda e variedade no atendimento. Todos esses fatores podem ou não, levar à satisfação. O tema satisfação vem sendo estudado desde quando surgiu o marketing, e a preocupação das empresas vem crescendo há muitos anos.

Para Kotler (2000), satisfação é a sensação de prazer ou desapontamento que resulta da comparação feita pelo comprador entre o desempenho (ou resultado) percebido de um produto e suas expectativas.

Manter clientes satisfeitos é muito importante, pois além de repetirem suas compras, transmitem às pessoas próximas sua satisfação com o produto e são muito menos propensos a mudar de empresa; enquanto que um cliente insatisfeito transmite ao dobro de pessoas sua insatisfação com o produto, podendo causar um grande transtorno, sendo também mais propensos a comprar do concorrente.

Os clientes insatisfeitos podem reclamar à empresa sua insatisfação ou simplesmente irem embora. A empresa que não deseja perder este cliente procura ouví-lo e, para que o número de clientes satisfeitos aumente, é preciso saber precisar satisfação, pois pode ser a chave para mudar o que está ruim, enfim, saber de seu consumidor o que falta para completar sua empresa.

A pesquisa de satisfação é uma das ferramentas mais importantes para obter respostas, pois é ela quem vai dizer o que o cliente realmente pensa e sugere. É um sistema de 
administração de informações que ouve o cliente, mede a qualidade dos produtos e serviços oferecidos pela empresa, auxiliando assim, futuras tomadas de decisões.

A relevância desse estudo se deve ao fato de, nos dias atuais, a satisfação ser uma das principais fontes para conquista da lealdade do consumidor, sendo um tema de grande importância, tanto na área empresarial quanto na área acadêmica. Fala-se muito em cliente e na orientação para o cliente. É um estudo importante, não só para a empresa em questão, mas também uma referência para outras empresas do setor que desejam fazer pesquisa de satisfação de clientes, já que é um setor de crescimento e há uma grande disputa no mercado. Levando em consideração os tipos de consumidores e suas exigências, as empresas desejam saber de seus clientes, os serviços que realmente os satisfazem e os pontos a melhorar para alcançarem a excelência em atendimento.

Toda essa discussão em torno do tema satisfação de clientes, gera uma pergunta a ser respondida: quais são os fatores que influenciam a satisfação (ou não) dos consumidores da concessionária Honda de Ituverava? Em que medida esses fatores influenciam?

De acordo com o problema de pesquisa levantado, o presente estudo teve como principal objetivo, identificar através de pesquisa, os principais fatores de influência na satisfação (ou não) dos consumidores da concessionária Honda da cidade de Ituverava e precisar a medida que cada um deles influenciam na satisfação desses consumidores.

\section{Hipótese a ser testada}

O atendimento e os serviços prestados pela concessionária são os principais fatores de influência na satisfação do consumidor.

\section{Hipótese Nula}

O atendimento e os serviços prestados pela concessionária não são os principais fatores de influência na satisfação do consumidor.

\section{Variáveis}

As variáveis deste trabalho que permitiram mensurar o nível de satisfação dos consumidores da concessionária são:

Atendimento: Para Kotler (20009), atender é ofertar vários serviços para resolução de problemas, assistência técnica, obter financiamentos aos clientes e agilização das entregas.

Serviço pós-venda: Segundo Kotler e Armstrong (2003), são atividades e benefícios oferecidos. São intangíveis e não resultam na posse de nada.

Marca: Para Kotler (2000) é um nome, termo, símbolo, desenho ou combinação destes que identifica os bens e serviços da empresa ou grupo de empresa e as diferencia da concorrência. 
Qualidade do produto: é o total de atributos e características de um produto ou serviço que influenciam sua capacidade de satisfazer necessidades declaradas ou implícitas (KOTLER, 2000).

Preço: é a quantia em dinheiro cobrada por um produto ou serviço. Pode-se também dizer que é a soma de valores que os consumidores trocam por benefícios de produtos ou serviços (KOTLER ; ARMSTRONG, 2003).

Promoções: Segundo Dias (2006) é a oferta de incentivos imediatos de curto prazo, por um patrocinador, com ou sem apoio de propaganda; com um fim de estimular a experimentação, aquisição ou repetição de compra. Deve ser usada por tempo limitado.

\section{Definição do universo e da amostra}

A concessionária vende uma média de 100 motos/mês, segundo o gerente responsável. Baseado nesses dados, o universo considerado pela pesquisa foi composto por homens e mulheres, sendo uma amostra de 50\% do total de 100 clientes que realizaram compras ou serviços na concessionária no mês de abril de 2009.

\section{Metodologia}

A satisfação de clientes em alguns casos pode ser algo difícil de se mensurar por meio de pesquisas. Mesmo com essa dificuldade, o que se propôs nesse trabalho foi chegar a resultados que permitissem avaliar o grau de satisfação/insatisfação com relação a alguns fatores. Para isso, foi realizado um levantamento (Survey) ${ }^{4}$ na concessionária Honda da cidade de Ituverava. A abordagem qualitativa deu-se por meio de entrevista com o gerente, precisando o nível dos serviços prestados e o treinamento dos funcionários. A abordagem quantitativa deu-se por meio de questionário pré-testado e aplicado aos clientes da concessionária, composto por duas questões discursivas e oito questões de múltipla escolha, precisando o nível de satisfação destes. Foi realizado também um levantamento bibliográfico para compor o referencial teórico, a fim de definir os conceitos de satisfação e das variáveis citadas anteriormente.

\section{REVISÃO DE LITERATURA}

Lemme et al. (1991) apresentaram o resultado de uma pesquisa exploratória de satisfação/insatisfação realizada com 158 pacientes que procuraram um hospital universitário da cidade do Rio de Janeiro para consulta inicial. Os pesquisadores buscaram medir o nível de

\footnotetext{
${ }^{4}$ Caracteriza-se pela pesquisa onde há interrogação direta das pessoas, cujo comportamento se deseja conhecer.
} 
satisfação/insatisfação dos usuários dos serviços do hospital com relação aos universitário da cidade do Rio de Janeiro para consulta inicial. Os pesquisadores buscaram medir o nível de satisfação/insatisfação dos usuários dos serviços do hospital com relação aos problemas do processo de atendimento. Os alunos que realizaram a pesquisa utilizaram-se de método de observação com relação aos problemas do processo de atendimento e aplicaram questionários e entrevistas para precisar os níveis de satisfação/insatisfação. Alunos e usuários conseguiram perceber os problemas do processo de atendimento citados acima, porém houve divergência de opiniões entre os dois grupos. Essa divergência deve-se às origens sociais diferentes e às expectativas diversas de ambos os grupos.

Procurando abranger um pouco mais o tema satisfação, Prado e Marchetti (1997) discutiram as dimensões da excelência em serviços em um supermercado, tendo por base a satisfação dos consumidores. A pesquisa foi baseada em uma escala de mensuração desenvolvida pelos mesmos autores no ano de 1996, onde eles aplicaram: pesquisa qualitativa, identificando as dimensões do conceito de satisfação e pesquisa quantitativa juntos às donas de casa. Participaram dessa amostra, 18 supermercados da região de Curitiba, Paraná. $\mathrm{O}$ autor observou a relação entre excelência e alguns fatores principais: eficácia no serviço de caixa, tecnologia e comunicação com os consumidores, atmosfera do supermercado, seções de padaria, carnes e frios, com atenção especial para os produtos de maior perecibilidade; cuidado com o tratamento pessoal oferecido aos clientes no caixa e em todo o supermercado.

Buscando medir o nível de satisfação dos consumidores do setor supermercadista, Révillion (1998), utilizou-se de pesquisa exploratória e descritiva. A pesquisa exploratória buscou aplicar entrevistas em profundidade com 15 consumidores do setor, e a pesquisa descritiva foi realizada com base em uma amostra de 400 consumidores dos supermercados de Porto Alegre, onde os questionários foram aplicados através de entrevistas pessoais. Os resultados demonstraram que o nível de satisfação dos consumidores com relação aos aspectos: conforto, conveniência, organização e infra-estrutura dos supermercados é mais alto do que o obtido pela dimensão de serviços. Concluiu-se também que, com base nos níveis de satisfação desses consumidores, existem algumas áreas que devem ser priorizadas para investimentos dentro dos supermercados, sendo elas: tecnologia utilizada, o mix de produtos, layout da loja e a segmentação adotada pelo estabelecimento.

Com base nos estudos realizados sobre satisfação, Beber (1999) pesquisou o atual estado das pesquisas de satisfação de consumidores, assim como também o da insatisfação e fidelização. O autor procurou seguir a mesma linha do artigo entitulado "A Satisfação dos 
consumidores: situação das pesquisas", escrito pelo professor Yves Evrard (Grupo HEC Paris), além de acrescentar novos conteúdos relacionados com o tema, usando de pesquisa bibliográfica. O autor conclui que o tema satisfação e insatisfação são de fundamental importância na atual realidade brasileira. Para as empresas, satisfação é uma consequência dos processos de qualidade e para os cidadãos, o tema é importante para que se tornem melhores consumidores, tornando-se um mercado qualitativo e exigente.

Dantas (2001) buscou analisar de modo aprofundado o confronto entre a teoria, o discurso e a prática no que diz respeito ao tema satisfação de clientes. A pesquisa teve como foco o setor de telecomunicações. Realizou-se um estudo comparativo por confrontação entre teoria, discurso e prática, utilizando-se de pesquisa exploratória (para fundamentação teórica), pesquisas qualitativas e quantitativas junto ao público consumidor dos serviços de telecomunicações. $\mathrm{O}$ universo considerado pela pesquisa foi composto por homens e mulheres clientes das operadoras de telecomunicações que atuam no Distrito Federal no período de abril e maio de 2001. Concluiu-se que a teoria vende uma imagem mitológica do cliente e é preciso acabar com isso; o discurso que predomina nas empresas é o de organizações que preocupam-se com o bem-estar da sociedade acima do lucro. Na prática, a visão do cliente mostra o contrário. Há uma preocupação mista que combina satisfação do cliente com lucratividade.

Seguindo com o objetivo de mensurar nível de satisfação e insatisfação de clientes, Arnhold (2007) realizou pesquisa em micro e pequenas empresas da agência do Banco do Brasil, na cidade de Abelardo Luz - SC. Através de um levantamento (survey), mensurou o grau de satisfação e insatisfação desses clientes na venda e pós-venda. Foi aplicado um questionário com 69 clientes micro e pequenas empresas dessa agência, que permitiu mensurar a satisfação dos clientes com relação à algumas variáveis de serviços: atendimento, funcionários, serviços de internet e atendimento telefônico, segurança, dentre tantas outras. Os resultados da pesquisa apontam caminhos para melhorar os níveis de satisfação dos clientes e permitem saber que os clientes estão satisfeitos com a maioria dos serviços prestados por essa agência.

\section{MATERIAL E MÉTODO}

\section{A empresa em estudo}

No presente trabalho, foi pesquisado um tipo de comércio varejista, especificamente uma concessionária de motos, que trabalha diretamente com a venda e prestação de serviços deste produto. A Moto Zema iniciou suas atividades há mais de trinta anos e durante todo este 
período apresentou um trabalho significativo na comercialização de consórcios e motocicletas da marca Honda. Hoje suas concessionárias despontam como líder do setor. A empresa possui concessionárias em Araxá, Uberaba e Ituverava, oferecendo uma completa linha de motos, peças, acessórios e serviços. A concessionária Honda do Grupo Zema escolhida para esta pesquisa foi a de Ituverava, que iniciou suas atividades no ano 2000, sendo uma empresa focada em vendas e serviços. Atualmente possui um quadro de 14 funcionários; sendo 1 gerente, 6 vendedores, 4 mecânicos, e 3 atendentes. Possui aproximadamente 6500 clientes diretos. A média de venda é de 100 motos/mês e possuem uma média de 300 motos/mês de clientes que realizam manutenção e compra de peças.

Em entrevista realizada com o gerente Mauro Renato de Oliveira Ribeiro, pode-se constatar que os treinamentos de vendas são feitos constantemente a cada lançamento de produto e podem ser feitos via internet, presenciais ou com instrutores altamente treinados pela fábrica. Logo após isso, os funcionários são avaliados por meio de uma prova aplicada no site, onde é emitido o certificado. A concessionária é visitada a cada 180 dias pelo consultor de serviços da fábrica, onde são avaliados itens como: padronização visual de todos os departamentos, instrumentos de medições, aferição de ferramentas especiais, instalações físicas, equipamentos de segurança, qualidade no atendimento, aparência visual dos funcionários, uso de produtos químicos não permitidos nas motocicletas etc. Anualmente a empresa realiza uma pesquisa para medir o índice de satisfação do cliente e conforme seu resultado, é montado um plano de ação. Todos os anos a Honda premia as 10 melhores concessionárias do país. No ano de 2008, a Moto Zema foi eleita a sexta empresa em satisfação ao cliente na área de serviços. Ela competiu com mais 720 concessionárias e recebeu nota 97,1 no quesito satisfação de cliente.

\section{Fatores de influência na satisfação do cliente}

Conforme dito por Kotler (2000), a satisfação de clientes pode ser o segredo para retenção destes, pois um cliente satisfeito é fiel por maior tempo, compra mais toda vez que a empresa lança novos produtos ou aperfeiçoa os existentes, fala bem da empresa e de seus produtos, dispende menor atenção à marcas e propaganda de concorrentes e é menos sensível a preço, oferece idéias sobre produtos e serviços à empresa e custa menos que um novo cliente para ser atendido, pois as transações são rotinizadas.

Em se tratando de atendimento, Whiteley (1992) acredita que estar próximo dos clientes é estar no caminho da vantagem competitiva. Quando a organização mede seus esforços pela satisfação de necessidades e expectativas dos clientes, estes verão suas expectativas sempre superadas, ficando encantados, respondendo com fidelidade. 
Quando as empresas e organizações estão voltadas para os clientes elas conseguem vantagem competitiva no mercado interno e externo e são capazes de cultivar funcionários satisfeitos (SHETH et al., 2001).

Kotler (2000) afirma que as empresas podem obter vantagem competitiva com uma equipe de profissionais bem treinados. Esses profissionais exibem algumas características: competência, cortesia, credibilidade, confiabilidade, capacidade de resposta e comunicação.

Em concordância com essa idéia, Almeida (1995) diz que para obter vantagem competitiva em produto o fator principal é a tecnologia, e em serviços é diferente, pois o ser humano é que faz a diferença. E é justamente aqui que aparece a vantagem competitiva.

Segundo a afirmação de Kotler (2000), quando o produto não é muito diferenciado, o sucesso pode estar na adição de serviços valorizados a esse produto ou até mesmo na melhoria de sua qualidade.

Sheth et al. (2001) afirma que para reter os clientes é necessário que as empresas dispendam de muito cuidado e preocupação após a compra.

O sucesso do marketing no mundo moderno e do futuro pertencerá às empresas que conseguirem agregar a maior quantidade de serviços relevantes aos seus produtos, conforme o momento e situação comportamental em que se recorrerão a eles (SOUZA, 1994).

Outro fator importante é a marca.

Segundo Kotler (2000) poucos clientes são fiéis à marca. Eles possuem atitudes com relação à marca, aqui estão alguns casos:

- O cliente troca de marca, sem fidelidade, geralmente por razões de preço.

- O cliente está satisfeito e não troca de marca;

- O cliente está satisfeito e terá custos se trocar de marca;

- O cliente valoriza a marca e a torna parte da sua vida;.

- O cliente é devoto à marca.

A satisfação também pode ser influenciada pela qualidade, e segundo Cobra (2009) “quando o produto é de qualidade inferior, não há serviço que satisfaça o consumidor". Quando se mantêm ou repara um produto de má qualidade, não estamos assegurando um serviço, e sim reparando um prejuízo.

Quanto melhor a qualidade da mercadoria de uma loja, mais os clientes desenvolverão lealdade em relação a ela (SHETH et al., 2001).

O preço foi estudado por Souza (1994) que diz que o conceito de preço no mundo moderno está muito associado a oferecer e garantir acessibilidade aos consumidores. 
Os clientes de hoje são mais difíceis de agradar, pois são inteligentes e conscientes com relação aos preços, são mais exigentes e mais facilmente abordados por concorrentes com ofertas melhores (KOTLER, 2000).

O consumidor brasileiro nem sempre tem consciência perfeita da relação qualidadepreço de um produto. Decidem a compra muitas vezes influenciados pela publicidade, pela oferta e por outros fatores gerais. Há sem dúvida outros fatores além do preço que influenciam a decisão de compra do consumidor, mas sem dúvida, o preço é o fator decisivo para a motivação de compra do consumidor (COBRA, 2009).

Um desses outros fatores estudado por Souza (1994) é a promoção, decisiva, onde se acerta na mosca ou erra-se de grotescamente. É nessa ferramenta de marketing que ocorrem as maiores e mais sensíveis modificações. É a que apresenta o maior número de novidades, que se renova dia - a - dia.

O gerente da linha de produtos costuma escolher um produto ou alguns itens de que dispõe para promover, geralmente isso é feito com os itens que não estão vendendo bem (KOTLER, 2000).

\section{ANÁLISE DOS DADOS COLETADOS}

Como citado anteriormente, foi realizada pesquisa com 50 consumidores da concessionária Moto Zema de Ituverava, dentre homens e mulheres. Os resultados obtidos permitiram a seguinte análise, e serão ilustrados pelos gráficos abaixo para melhor visualização.
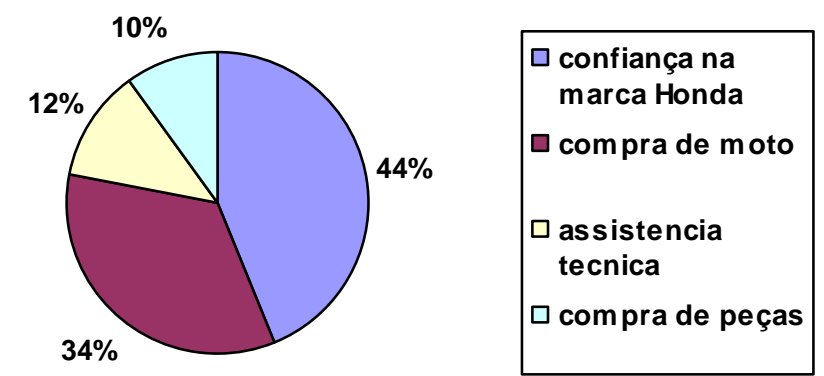

Gráfico 1 - Motivo de procura dos consumidores pela concessionária Moto Zema.

Ao serem perguntados sobre o motivo da procura pela concessionária Honda, a maioria dos entrevistados (44\%), disseram que foram motivados a procurar a concessionária por confiar na marca Honda; $34 \%$ declararam motivação exclusiva pela compra de moto, o que ressalta que estas pessoas que compraram também foram atraídas pela confiabilidade na 
marca Honda; $12 \%$ foram em busca de serviço de assistência técnica e um percentual pequeno (10\%) de pessoas, declararam ter ido à concessionária para comprar peças e outros equipamentos para motos. Esses dados nos permitem dizer que do grande percentual de pessoas que compram a moto Honda por confiar na marca, uma quantidade muito pequena retorna para realizar serviço de assistência técnica.
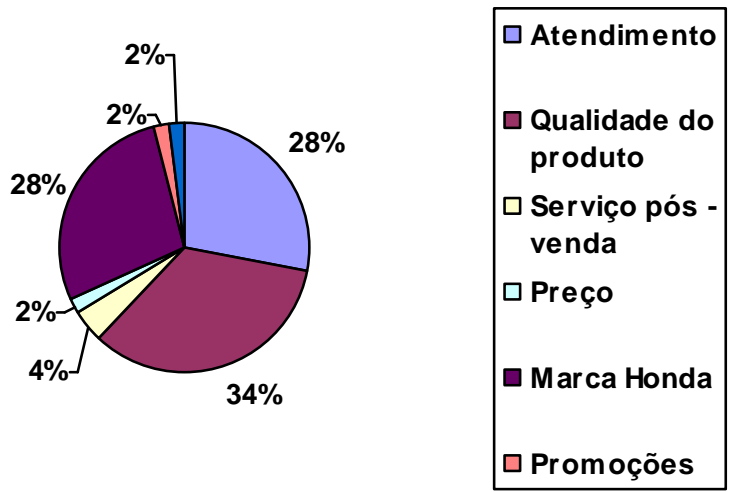

Gráfico 2 - Fatores de maior influência na satisfação do consumidor da concessionária Moto Zema.

Nota-se pelo Gráfico 2 que com relação à fatores de satisfação, 34\% dos entrevistados que foram atendidos na concessionária, ficaram satisfeitos com a qualidade da moto comprada. No mesmo nível de satisfação causada nos consumidores, aparecem atendimento e a Marca Honda, com 28\%. Em seguida, um percentual muito pequeno de pessoas entrevistadas (4\%) declararam como maior fator de satisfação, o serviço pós - venda ; na sequência vieram promoções e preço com $2 \%$ de satisfação declarada pelos entrevistados.

Apenas $2 \%$ destes, citaram como outro motivo de satisfação, o serviço de assistência técnica.
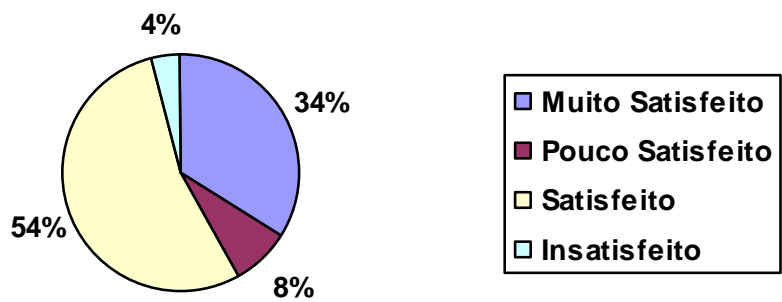

Gráfico 3 - Satisfação do consumidor com o atendimento fornecido pela concessionária Moto Zema.

O Gráfico 3 permite ver que a maioria dos entrevistados (54\%), ficaram satisfeitos com o atendimento da concessionária e $34 \%$ ficaram muito satisfeitos, totalizando $88 \%$ de satisfação. Somente $8 \%$ das pessoas declararam pouca satisfação com o atendimento, restando 
um percentual muito pequeno (4\%) de insatisfeitos, totalizando $12 \%$ de insatisfação. Existem mais pessoas satisfeitas do que insatisfeitas com o atendimento da concessionária.
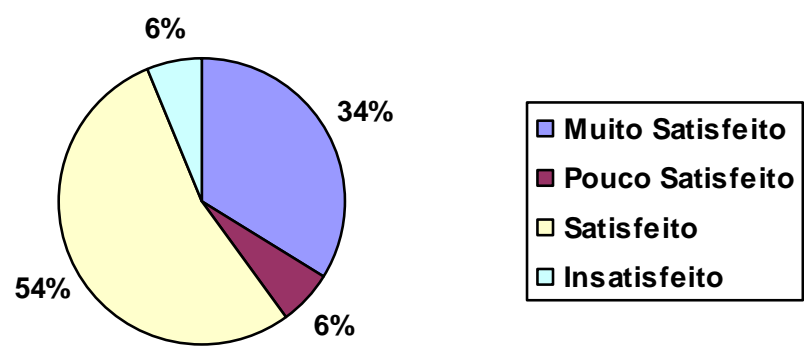

Gráfico 4 - Satisfação do consumidor com o serviço pós - venda oferecido pela concessionária Moto Zema.

Quando perguntados sobre a satisfação com o serviço pós - venda, 54\% dos entrevistados disseram-se satisfeitos, $34 \%$ ficaram muito satisfeitos e um pequeno percentual de pessoas (6\%) ficaram pouco satisfeitos. Com o mesmo percentual (6\%), aparecem os insatisfeitos. O Gráfico 4 permite visualizar que a maioria das pessoas estão satisfeitas com o serviço pós - venda da concessionária.
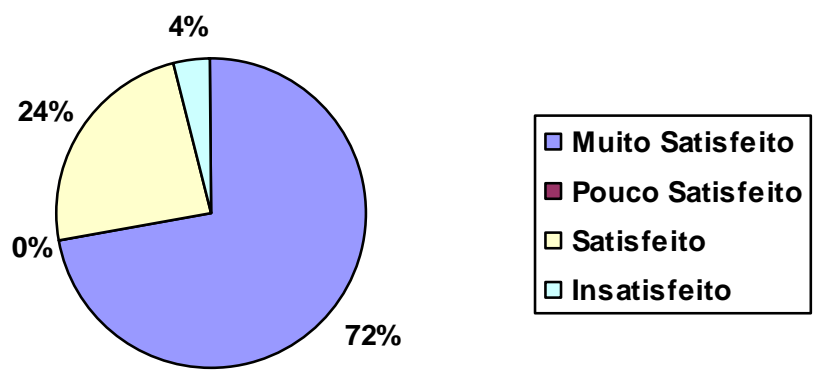

Gráfico 5 - Satisfação do consumidor com a marca do produto ofertado pela concessionária Moto Zema.

Ao serem perguntados sobre a marca Honda, $72 \%$ das pessoas declararam estar muito satisfeitas, sendo um percentual muito grande em comparação com os $24 \%$ de satisfeitos e $4 \%$ de insatisfeitos. Nenhuma pessoa declarou pouca satisfação com a marca, o que mostra que a Honda é uma marca que causa grande satisfação nos consumidores de moto e está atrelada à confiabilidade que os consumidores têm por essa marca, como já foi verificado no começo da análise. 

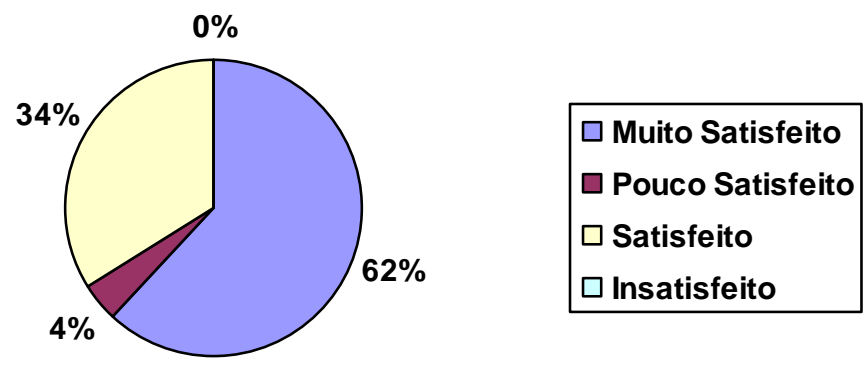

Gráfico 6 - Satisfação do consumidor com a qualidade do produto oferecido pela concessionária Moto Zema.

Ainda com relação ao produto, quando perguntado sobre a qualidade da moto, pode-se verificar que a maioria das pessoas (62\%) ficaram muito satisfeitas, $34 \%$ ficaram satisfeitas e apenas $4 \%$ dos entrevistados ficaram pouco satisfeitos. A pesquisa não apontou nenhuma pessoa insatisfeita com a qualidade da moto, mostrando que a moto Honda é definida pelos seus consumidores como sendo um produto de altíssima qualidade, principalmente quando citado com outros fatores de satisfação conforme demonstra no gráfico 2.

Isso também permite dizer que o produto está atrelado à marca e a confiabilidade da Honda.
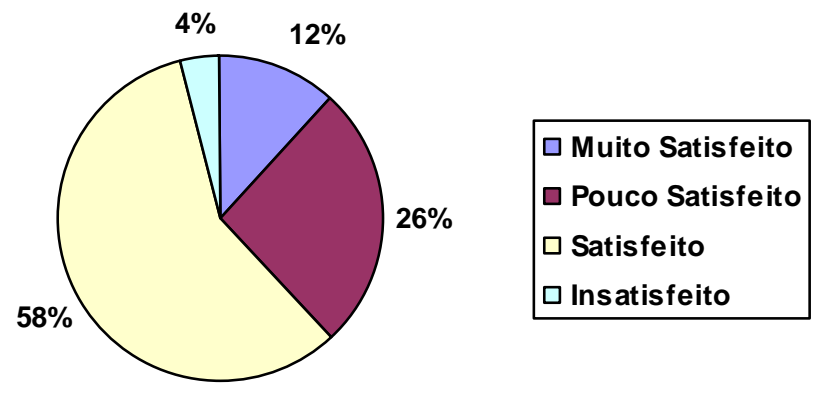

Gráfico 7 - Satisfação do consumidor com o preço estabelecido pela concessionária Moto Zema.

Quando o fator de satisfação em questão é o preço, apenas $4 \%$ disseram-se insatisfeitos com o preço da moto. Esse resultado mostra que o percentual de satisfeitos é muito maior que o de insatisfeitos, o que leva a crer que o preço não é muito importante na decisão de compra da moto, já que mesmo os insatisfeitos, compraram a moto ou realizaram serviços na concessionária. 


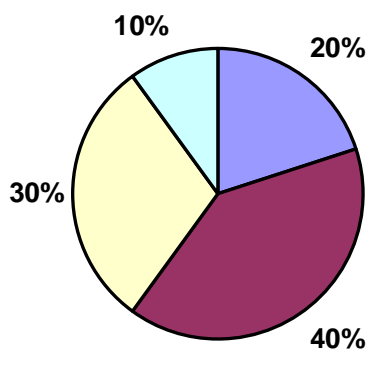

$\square$ Muito Satisfeito

$\square$ Pouco Satisfeito

$\square$ Satisfeito

口Insatisfeito

Gráfico 8 - Satisfação do consumidor com as promoções oferecidas pela concessionária Moto Zema.

Com relação às promoções realizadas pela concessionária, $40 \%$ dos entrevistados mostraram pouca satisfação estas, enquanto que $30 \%$ se dizem satisfeitos, $20 \%$ declararam muita satisfação e o restante dos entrevistados (10\%), ficaram insatisfeitos com esse fator. Conforme visto anteriormente na análise da pesquisa, o fator promoções causou pouca influência na satisfação do consumidor quando comparado com outros fatores, porém quando analisado a parte, metade dos consumidores declararam satisfação quando houve a realização desta no compra do produto Honda.

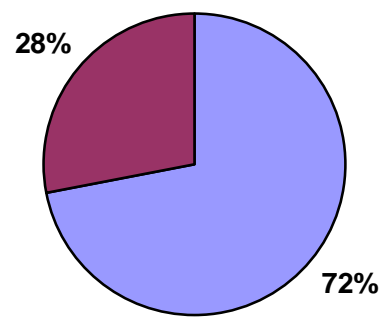

$\square$ Satisfeito

$\square$ Insatisfeito

Gráfico 9 - Satisfação do consumidor com o produto, serviço adquirido e forma de entrega da concessionária Moto Zema.

Conforme mostra o Gráfico 9, quando perguntado aos consumidores da concessionária sobre satisfação com o produto ou serviço adquirido e a forma de entrega, pode-se observar que de maneira geral, uma maioria de $72 \%$ dos clientes ficaram satisfeitos e $28 \%$ dos clientes da concessionária ficaram insatisfeitos com esses itens.

Na mesma questão, foi solicitado aos consumidores que sugerissem melhorias no sentido de aumentar o nível de satisfação com a concessionária. Podemos identificar melhor essas sugestões, na Tabela 1 a seguir: 
Tabela 1 - Melhorias sugeridas pelos consumidores da concessionária Moto Zema

\begin{tabular}{l|c}
\hline \multicolumn{1}{c|}{ Sugestões de melhoria } & Percentual de pessoas (\%) \\
\hline Promoções & 16 \\
Serviço de assistência técnica & 12 \\
Preço & 8 \\
Entrega & 8 \\
Reposição de peças & 6 \\
Atendimento da concessionária & 4 \\
Não sugerida & 46 \\
\hline Total de entrevistados & $\mathbf{1 0 0}$ \\
\hline
\end{tabular}

Do percentual total de entrevistados, $16 \%$ sugeriram melhorias nas promoções realizadas pela concessionária, $12 \%$ dizem que o que deve melhorar é o serviço de assistência técnica, $8 \%$ sugerem melhorias para o preço e entrega da moto, $6 \%$ citaram sugestões de melhorias para reposição de peças e um pequeno percentual de $4 \%$ dos entrevistados sugeriram melhorias no atendimento da concessionária. Do total de entrevistados, $46 \%$ não citaram sugestões de melhoria.

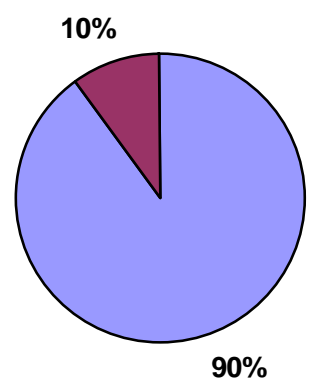

$\square$ Satisfeitos

$\square$ Insatisfeitos

Gráfico 10 - Satisfação geral do consumidor com a concessionária Moto Zema.

De forma geral, o Gráfico 10 permitiu verificar que referente à satisfação com a concessionária e o fator de maior influência, verificou-se, que a maioria dos clientes estão satisfeitos e uma minoria estão insatisfeitos com a concessionária.

Ficou claro, pela pesquisa, que a satisfação do consumidor da concessionária Honda Moto Zema, foi influenciada, em sua maior parte, pelos seguintes fatores: atendimento, marca Honda e a qualidade do produto, que traz como consequência a confiabilidade.

\section{CONSIDERAÇÕES FINAIS}

O presente trabalho objetivou através de um levantamento ( Survey), identificar os 
principais fatores de influência na satisfação dos consumidores da concessionária Honda de Ituverava e saber em que medida eles influenciam a satisfação (ou não) desses consumidores.

Em princípio, apresentou-se como hipótese de pesquisa, o atendimento e os serviços prestados pela concessionária como sendo os principais fatores de influência na satisfação, porém os resultados da pesquisa nos permitiram rejeitar essa hipótese e aceitar a hipótese nula, já que os consumidores apontaram como maiores fatores de influência de sua satisfação $\mathrm{o}$ atendimento e a marca do produto.

Vale lembrar, que o serviço prestado, havia sido citado pelo gerente como ponto forte da concessionária, porém a análise permite dizer que a empresa deve continuar investindo em atendimento, que de modo geral vai ao encontro da satisfação do cliente e deve intensificar seus esforços nas promoções e serviço de assistência técnica, já que foram os fatores que mais apareceram em sugestões de melhoria dos clientes. Na pesquisa pode-se observar, que preço e promoções, quando comparados com outras variáveis de atendimento, destacam-se pouco, porém, quando questionados à parte, compuseram maior satisfação do que insatisfação nos consumidores.

Os resultados mostraram que existe um maior percentual de pessoas concentrados em compra de moto, embora a concessionária tenha informado que possui um maior número de clientes de serviços. Por todas essas análises e conforme sugestões de melhoria citadas pelos respondentes da pesquisa, fica claro que o produto e a marca Honda são de alta confiabilidade e que as pessoas foram atraídas em sua maior parte pela qualidade do produto e ficaram satisfeitas com o atendimento que receberam na concessionária.

Com base nesse trabalho, recomenda-se que seja feito um estudo mais amplo a respeito da satisfação dos consumidores da concessionária Honda, ampliando-se a amostra com os consumidores das concessionárias Moto Zema de Araxá e Uberaba. No tópico de estudo da empresa, pode-se verificar que é realizada uma pesquisa anual para medir o Índice de Satisfação dos Clientes (ISC), sugere-se confrontar, se possível, os resultados de próximos levantamentos, com a pesquisa de satisfação realizada anualmente por essas concessionárias, já que não foi possível o acesso a esses dados para melhor resultado e avaliação dessa pesquisa.

\section{REFERENCIAS}

ALMEIDA, S. Cliente, eu não vivo sem você: o que você não pode deixar de saber sobre qualidade em serviços e clientes. 18 ed. Salvador: Casa da Qualidade, 1995. 
ARNHOLD, C. J. Grau de satisfação dos clientes do segmento micro e pequenas empresas na agência de Abelardo Luz (SC). Santa Catarina, 2007. Monografia (Curso de Especialização em Gestão de Negócios Financeiros) - Programa de Pós-Graduação em Administração, Departamento de Administração, Universidade Federal do Rio Grande do Sul. Disponível em:<http:// www.lume.ufrgs.br/bitstream /handle/10/83/14792/000669107. pdf > . Acesso em: 25 mar. 2009.

BEBER, S.J.N. Estado atual dos estudos sobre a satisfação do consumidor. In: ENCONTRO ANUAL DA ASSOCIAÇÃO NACIONAL DOS PROGRAMAS DE PÓS-GRADUAÇÃO EM ADMINISTRAÇÃO - ENANPAD , 23, 1999, Foz do Iguaçu. Anais... Foz do Iguaçu:

ANPAD, 1999. Disponível em: <http://www.anpad.org.br/enanpad/1999/dwn/ enanpad1999mkt.29.pdf $>$. Acesso em: 03 mar. 2009.

COBRA, M. Marketing básico: uma perspectiva brasileira. 4. ed. São Paulo: Atlas, 2009.

DANTAS, E.B. Satisfação do cliente: um confronto entre a teoria, o discurso e a prática. Santa Catarina, 2001. Dissertação (Mestrado em Engenharia de Produção) - Programa de Pós-Graduação em Engenharia de Produção, Departamento de Engenharia de Produção, Universidade Federal de Santa Catarina. Disponível em: < http:

//www.edmundobdantas.com/arquivos/mestrado.pdf>. Acesso em: 28 mar. 2009.

DIAS, S.R. (Org). Gestão de marketing. São Paulo: Saraiva, 2006.

KOTLER, P. Administração de marketing. 10. ed. São Paulo: Prentice Hall, 2000.

KOTLER, P.; ARMSTRONG, G. Princípios de marketing. 9. ed. São Paulo: Prentice Hall, 2003.

LEMME, A. C. et al. A satisfação do usuário em hospital universitário. Revista de Saúde Pública. São Paulo, v.25, n.1, p. 41-46, 1991. Disponível em:

<http://www.scielo.org/pdf/rsp/v25n1/09.pdf>. Acesso em: 25 mar. 2009.

PRADO, P.H.M.; MARCHETTI, R. Excelência em supermercados: a dimensão da satisfação do consumidor. RAUSP. São Paulo, v.32, n.2, p. 58 - 64, abr. / jun.1997. Disponível em: <http://www.rausp.usp.br>. Acesso em: 28 mar. 2009.

RÉVILLION, A. S. P. Um estudo sobre a satisfação do consumidor com o setor supermercadista em Porto Alegre. Porto Alegre, 1998. Dissertação (Mestrado em Administração com ênfase em Marketing) - Programa de Pós-Graduação em Administração, Departamento de Administração, Universidade Federal do Rio Grande do Sul. Disponível em: <http://volpi.ea.ufrgs.br/tesesedissertacoes/td/000096.pdf>. Acesso em: 25 mar. 2009.

SHETH, Jagdhish N. et al. Comportamento do cliente: indo além do comportamento do consumidor. São Paulo: Atlas, 2001.

SOUZA, Francisco Alberto Madia de. Introdução ao marketing de ${ }^{\mathbf{a}}$ geração: datamarketing behavior. São Paulo: Makron Books, 1994. 